\title{
ALFABETIZAÇÃO NA EJA E OS INDICADORES DO INAF: UM OLHAR FRENTE ÀS PRÁTICAS PEDAGÓGICAS
}

\author{
Maria Eurácia Barreto de Andrade ${ }^{1}$ \\ Thaís Costa de Freitas ${ }^{2}$
}

\section{RESUMO}

O presente artigo apresenta reflexões sobre Alfabetização e Práticas Pedagógicas na Educação de Jovens e Adultos (EJA), como recorte de uma pesquisa mais ampla, realizada no Colégio Entre Fios, no ano de 2018, objetivando compreender se as práticas pedagógicas realizadas nos últimos anos do Ensino Médio na EJA contribuem com o processo de alfabetização; para tanto, foram aplicadas situações do INAF com educandos da EJA do terceiro tempo formativo, nos eixos VI e VII. No âmbito metodológico, constitui-se como uma pesquisa qualitativa, com imersão no estudo de caso. Nessa tessitura, respaldam nossos estudos, prioritariamente, as teorias de Paulo Freire $(2003,2014,2015$, 2018), Miguel Arroyo (2005, 2015, 2017), dentre outros que contribuem para melhor compreender a temática em tela, além de pesquisas realizadas em meios eletrônicos e revistas, que nos permitem tecer relevantes fios sobre a referida abordagem. Nessa trama que engloba alfabetização no lócus da pesquisa, podemos perceber que os estudantes pesquisados apresentam níveis

\footnotetext{
${ }^{1}$ Professora Doutora da Universidade Federal do Recôncavo da Bahia (UFRB), com atuação no Cento de Formação de Professores (CFP). Líder e Pesquisadora do Núcleo Carolina Maria de Jesus: Estudo, Pesquisa e Extensão em Educação Popular, Agroecologia e Alfabetização da Classe Trabalhadora, vinculada ao Programa de Extensão Tecelendo (UFRB/CFP). ORCID: https://orcid.org/0000-0001-9910-0527 E-mail: mariaeuracia@ufrb.edu.br.

2 Mestranda no Programa de Pós-Graduação em Educação (PPGED) pela Universidade Estadual do Sudoeste da Bahia (UESB). Especialista em Educação e Interdisciplinaridades pela Universidade Federal do Recôncavo da Bahia (UFRB). Graduada em Licenciatura em Pedagogia pela UFRB. Pesquisadora do Núcleo Carolina Maria de Jesus: Estudo, Pesquisa e Extensão em Educação Popular, Agroecologia e Alfabetização (UFRB-CFP). Membro do Laboratório de Estudos e Pesquisas em Ensino de História (LAPEH/UESB). ORCID: https://orcid.org/0000-0002-7626-8025. E-mail: thais_costa15@hotmail.com
} 
assustadores de analfabetismo, considerando que já estão na última etapa da Educação Básica. O resultado deste estudo evidencia a necessidade de investimento com políticas públicas voltadas para a Educação de Jovens e Adultos; a relevância da formação de profissionais na área e a necessidade de se refletir sobre a alfabetização no âmbito do Ensino Médio, no considerado "ensino regular".

Palavras-chave: Educação. Alfabetização de Jovens e Adultos. Analfabetismo.

\section{LITERACY AT EJA AND INAF INDICATORS: A LOOK ACROSS PEDAGOGICAL PRACTICES}

\section{ABSTRACT}

This article presents reflections on Literacy and Pedagogical Practices in the Youth and Adult Education (EJA), as part of a broader research, carried out at Colégio Entre Fios, in 2018, aiming to understand if the pedagogical practices carried out in the last years of High School in the EJA contribute to the literacy process; for this purpose, INAF situations were applied with EJA students from the third training period, in axes VI and VII. In the methodological scope, it is a qualitative research, with immersion in the case study. We bring, in this texture, to support our studies, primarily the theories of Paulo Freire (2003, 2014, 2015, 2018), Miguel Arroyo (2005, 2015, 2017), among others that contribute to better understanding the theme at hand, in addition to a research carried out in electronic media and magazines, which allow us to better understand relevant threads about this approach. In this plot that encompasses literacy in the locus of research, we can see that the students surveyed have frightening levels of iliteracy, considering that they are already in the last stage of Basic Education. The result of this study highlights the need for investment in public policies aimed at the Education of Young people and Adults; the relevance of training professionals in the area and the need to reflect on literacy in the context of high school, in what is considered "regular education". 
Keywords: Education. Literacy for youth and adults. Illiteracy.

\section{ALFABETIZACIÓN EN LA EJA E LOS INDICADORES DEL INAF: UNA MIRADA A TRAVÉS DE PRÁCTICAS PEDAGÓGICAS}

\section{RESUMEN}

Este artículo presenta reflexiones sobre Alfabetización y Prácticas Pedagógicas en Educación de Jóvenes y Adultos, como parte de una investigación más amplia, realizada en el Colégio Entre Fios, en 2018, con el objetivo de comprender si las prácticas pedagógicas realizadas en los últimos años de Educación Secundaria en EJA contribuyen al proceso de alfabetización; para ello, se aplicaron situaciones del INAF con alumnos de EJA del tercer período formativo, en los ejes VI y VII. En el ámbito metodológico, se trata de una investigación cualitativa, con inmersión en el estudio de caso. Traemos, en esta textura, para sustentar nuestros estudios, principalmente las teorías de Paulo Freire (2003, 2014, 2015, 2018), Miguel Arroyo (2005, 2015, 2017), entre otras que contribuyen a comprender mejor el tema en por otra parte, además de las investigaciones realizadas en medios electrónicos y revistas, que nos permiten tejer hilos relevantes sobre este enfoque. En esta trama que engloba la alfabetización en el locus de investigación, podemos observar que los estudiantes encuestados tienen niveles de analfabetismo alarmantes, considerando que ya se encuentran en la última etapa de Educación Básica. El resultado de este estudio destaca la necesidad de invertir en políticas públicas orientadas a la Educación de Jóvenes y Adultos; la relevancia de la formación de profesionales en el área y la necesidad de reflexionar sobre la alfabetización en el contexto del bachillerato, en lo que se considera "educación regular"

Palabras clave: Educación. Alfabetización para jóvenes y adultos. Analfabetismo. 


\section{INTRODUÇÃO}

O analfabetismo da população jovem e adulta, segundo Sá (2016), vem se constituindo como um problema histórico e isso denuncia a urgência de visibilizar esta temática na ordem do dia das discussões e pesquisas, tanto nos espaços acadêmicos de formação quanto nos demais espaços educativo-formativos, para que cheguem ao poder público como tensionamento à necessidade de políticas públicas e ações efetivas que possam mitigar uma dívida social a estes sujeitos não alfabetizados, uma vez que a alfabetização é um direito constitucional que deve ser garantido a todos e todas, sem distinção.

Discutir, pesquisar e problematizar sobre a Alfabetização e Práticas Pedagógicas no Ensino Médio da EJA pode parecer estranho, considerando que espera-se que todos os estudantes inseridos na última etapa da Educação Básica na modalidade já estejam alfabetizados no seu sentido pleno. No entanto, o que se presencia cotidianamente são jovens e adultos que concluem os estudos básicos sem a garantia de um alfabetismo funcional pleno ou com nível proficiente.

Assim, evidenciamos os dados do Indicador Nacional de Alfabetismo ${ }^{3}$ Funcional (Inaf), que diferentemente dos indicadores do Instituto Brasileiro de Geografia e Estatística (IBGE) revelam dados não apenas no âmbito da compreensão dos entrevistados acerca da sua interação com a leitura e escrita, mas implica, sobretudo, na aplicação de um teste com situações do cotidiano, no sentido de verificar as interações e habilidades destes com as práticas sociais em que a leitura e a escrita estão inseridas.

Nesta perspectiva, precisamos destacar que embora exista uma gama de pesquisas referentes à Educação de Jovens e Adultos (EJA) e a alfabetização, a Alfabetização de Jovens e Adultos (AJA) é uma área que ainda carece de mais pesquisas e de um olhar mais cuidadoso acerca dos temas que Ihe constituem. Dentro desse

${ }^{3} \mathrm{O}$ alfabetismo, segundo o Inaf, diz respeito à capacidade não somente de compreender, mas, sobretudo, utilizar e refletir sobre as mais diversas informações de leitura e escrita, de modo que possa participar ativamente dos eventos e práticas sociais nos seus mais diversos âmbitos. 
universo, precisamos trazer à luz os altos índices de analfabetismo, visto que, de acordo com a Pesquisa Nacional por Amostras de Domicílios (BRASIL, 2020), a taxa de pessoas não alfabetizadas no Brasil é de aproximadamente 11.000 .000 (onze milhões), o que se refere a $6,6 \%$ da nossa população com 15 (quinze) anos ou mais.

Nessa conjectura, a pesquisa ainda demonstra que a região Nordeste apresenta a maior faixa de analfabetismo do país, representando $56,2 \%$, o que significa quase 6,2 milhões de pessoas, seguido das regiões Norte e Centro Oeste e por conseguinte Sul e Sudeste. O número de pessoas não alfabetizadas com 60 (sessenta anos) ou mais representa $18 \%$, ou seja, aproximadamente 6.000 .000 (seis milhões) nessa faixa etária.

A pesquisa ainda menciona que uma das questões referentes ao analfabetismo está vinculada diretamente ao fator idade, conforme demonstrado a seguir.

Nota-se que, no Brasil, o analfabetismo está diretamente associado à idade. Quanto mais velho o grupo populacional, maior a proporção de analfabetos. Em 2019, eram quase 6 milhões de analfabetos com 60 anos ou mais, o que equivale a uma taxa de analfabetismo de $18,0 \%$ para esse grupo etário. Ao incluir, gradualmente, os grupos etários mais novos, observa-se queda no analfabetismo: para $11,1 \%$ entre as pessoas com 40 anos ou mais, 7,9\% entre aquelas com 25 anos ou mais e $6,6 \%$ entre a população de 15 anos ou mais. Esses resultados indicam que as gerações mais novas estão tendo um maior acesso à educação e sendo alfabetizadas ainda enquanto crianças. Por outro lado, os analfabetos continuam concentrados entre os mais velhos e mudanças na taxa de analfabetismo para esse grupo se dão, em grande parte, devido às questões demográficas como, por exemplo, o envelhecimento da população. (BRASIL, 2020, p. 2).

Mergulhados nessas linhas, a investigação buscou compreender se as práticas pedagógicas realizadas nos últimos anos do Ensino Médio na EJA contribuem com o processo de alfabetização. 
E para tal, imergimos na busca pelas repostas para nossas interrogações. Com isso, utilizamos a pesquisa qualitativa do tipo Estudo de Caso e para produção dos dados aplicamos situações do INAF $^{4}$ com os educandos do terceiro tempo formativo da EJA, nos eixos VI e VII. O lócus da pesquisa foi o colégio Entre Fios ${ }^{5}$.

Como aporte teórico, respaldamo-nos nas obras de Paulo Freire, tais como: A importância do ato de ler (2003), Alfabetização leitura do mundo, leitura da palavra (2013), Pedagogia da Autonomia (2015), Pedagogia da Esperança (2018), Pedagogia do Oprimido (2014); e as obras de Miguel Arroyo: Educação de Jovens e Adultos: um campo de direitos e de responsabilidade pública (2005), O humano é viável? É educável? (2015), Passageiros da Noite - do trabalho para a EJA: itinerários pelo direito a uma vida justa (2017).

A intenção deste artigo é proporcionar outros olhares para a discussão da EJA e suas especificidades e também fomentar debates que englobem a modalidade e questões referentes ao currículo, às práticas pedagógicas, às metodologias, ao financiamento e investimento para educação de jovens e adultos.

\section{TRILHA METODOLÓGICA: Caminhos percorridos}

A trilha metodológica percorrida foi a da pesquisa de abordagem qualitativa, a qual traz em seus pressupostos um reconhecimento e uma interpretação dos aspectos mais minuciosos e complexos do comportamento humano, o qual "[...] fornece análise mais detalhada sobre investigações, hábitos, atitudes e tendências de comportamentos." (LAKATOS; MARCONI, 2005, p. 269).

A investigação apoia-se no Estudo de Caso, caracterizado por coletar e analisar informações sobre determinados sujeitos, comunidades, locais, grupos, com objetivo de compreender os

\footnotetext{
${ }^{4}$ Representa uma iniciativa do Instituto Paulo Montenegro - Ação Social do IBOPE e da ONG Ação Educativa que tem como objetivo basilar, segundo Ribeiro (2003, p. 9), "oferecer a sociedade brasileira um conjunto de informações sobre habilidades e práticas relacionadas à leitura, escrita e matemática da população brasileira, de modo a fomentar o debate público e subsidiar a formulação de políticas de educação e cultura".

${ }^{5} \mathrm{O}$ nome do lócus pesquisado é fictício, a fim de preservar a identidade e respeitar os princípios éticos da pesquisa.
} 
diversos aspectos referentes ao objeto da pesquisa (LÜDKE; ANDRÉ, 1986), tendo como instrumento para produção de dados as situações do Indicador de Alfabetismo Funcional (INAF) que surge no ano de 2001, como um estudo para medir os níveis de Alfabetismo da população brasileira. Estes "[...] procuram abarcar a complexidade do fenômeno tanto na dimensão das habilidades cognitivas quanto das práticas sociais nos diversos contextos de vivência dos jovens e adultos entre 15 e 64 anos". (INAF, 2018, p. 4).

Nessa trama, o INAF compreende o alfabetismo como a capacidade de utilização e compreensão e reflexão da informação escrita. Nesse ambiente, estão englobados: o reconhecimento dos elementos escritos, operações cognitivas mais complexas que envolvam a integração de informações textuais e quais as visões do mundo para o leitor. Por exemplo, conexões lógicas, noções e operações matemáticas, letramento, etc. (INAF, 2018).

Desde o seu nascimento até o ano de 2005 os levantamentos de dados ocorriam anualmente com ênfase na leitura, escrita e matemática. A partir de 2007 foram incorporados outros avanços metodológicos e ele passou a acontecer em intervalos mais longínquos, com edições em 2009, 2011, 2015 e a última edição em 2018 (INAF, 2018). O indicador de Alfabetismo Funcional $(2018$, p. 6) é um estudo organizado

[...] com base em um teste cognitivo e um questionário contextual. Os itens que compõem o teste de Alfabetismo envolvem a leitura e interpretação de textos do cotidiano (bilhetes, notícias, instruções, textos narrativos, gráficos, tabelas, mapas, anúncios, etc.). O questionário contextual aborda características sociodemográficas e práticas de leitura, escrita e cálculo que os sujeitos realizam em seu dia a dia.

As situações do INAF foram aplicadas com 10 (dez) educandos do colégio Entre Fios do tempo formativo três, pois é o eixo que compreende o Ensino Médio na EJA, 05 (cinco) do eixo VI e 05 (cinco) 
do eixo VII ${ }^{6}$. As situações textuais do INAF levam um grande tempo para sua aplicação, pois solicitam dos sujeitos mais do que respostas "automáticas", exigem que leiam, reflitam para responder às questões e sua aplicação deve ocorrer individualmente, necessitando que o pesquisador tenha sensibilidade, paciência, respeito e atenção para não acabar influenciando na hora das respostas.

$\mathrm{Na}$ aplicação deste instrumento, tivemos diversos contratempos, isto é: alguns educandos não conseguiam fazer a leitura das questões, outros necessitavam que lessem as questões pelo menos três vezes para que respondessem, além disso, por estarem em períodos chuvosos ${ }^{7}$ no município pesquisado, a maioria dos educandos não comparecia ao Colégio, pois os ônibus não circulavam.

Esse instrumento compôs-se de 10 (dez) situações que abarcavam a interpretação de textos cotidianos (notícias, receitas, bilhetes, gráficos, tabelas, anúncios, textos narrativos, etc.). O questionário contextual abordava características sociais, demográficas, práticas de leitura e cálculos que os educandos utilizam no dia a dia, para que pudéssemos perceber em qual nível de Alfabetismos, de acordo com as escalas do INAF, os sujeitos se encontravam (Não alfabetizado ${ }^{8}$, Rudimentar, Elementar, Intermediário e Proficiente).

\section{EJA: Um território de lutas, de direitos}

Adentrar na Educação de Jovens e Adultos significa mergulhar num universo de encantos, vivências, saberes, encontros e trocas. Diversos fios tecidos que formam um artesanato repleto de histórias, memórias e experiências. Compreendemos que definir a modalidade implica expor um território de disputas, lutas. Enquanto modalidade de ensino da Educação Básica, objetiva oportunizar a inclusão de uma

${ }^{6} \mathrm{O}$ eixo $\mathrm{VI}$ compreende as disciplinas das áreas de humanas e o eixo VII compreende as disciplinas das exatas.

${ }^{7}$ Importante destacar que a maioria dos alunos do terceiro tempo formativo era residente da Zona Rural.

8 No INAF eles utilizam o termo Analfabeto, mas no nosso trabalho e nas interpretações utilizaremos: Não alfabetizados. 
parcela da população que não pôde estudar na considerada "idade regular".

Quando seguimos os fios que compõem a EJA, estamos buscando trazer ao debate os tensionamentos de homens e mulheres na busca pela inclusão no campo educacional, os quais buscam as garantias dos seus direitos e autonomia, uma vez que tiveram seu acesso negado a este cenário por questões atravessadas pelas demandas sociais, políticas, econômicas, históricas, territoriais, de gênero, de idade, entre outras.

Em diálogo com as linhas que atravessam e tecem a Educação de Jovens e Adultos, um dos pontos que merecem destaque é o sentido da EJA, pois em diversas circunstâncias é entendida/vista como uma forma de compensação/complementaridade/reparação do sistema que não oportunizou a inserção/ingresso dos sujeitos na educação básica na idade considerada "própria10". Desse modo, muitas vezes, a modalidade é entendida

[...] como uma educação "tapa buracos", destinada a remediar as falhas dos sistemas social e educativo, encarregada de ensinar àqueles adultos que deveriam ter aprendido na escola, quando crianças; [...] uma educação de pobres e para pobres, como um remédio, uma educação compensatória. (TORRES, 1995, p. 28).

Nessa conjectura, ressaltamos que a educação acontece ao longo da vida e é atravessada por diversos aspectos, diferentes lugares, cenários, sujeitos. Voltamos nossos olhares aos jovens, adultos, homens, mulheres que buscam a oportunidade de não vivenciarem os estigmas de que são vítimas quando são identificados socialmente como "analfabetos ${ }^{11 " .}$

\footnotetext{
${ }^{9}$ Nesse momento, e por uma questão de posição política, precisamos fazer alguns questionamentos: existe idade certa para aprender? A aprendizagem está condicionada à idade? Ou a aprendizagem é um processo contínuo, que ocorre no decorrer da vida? Questões que acreditamos terem importância para a discussão da EJA e da formação humana.

10 Seguiremos tensionando se existe tempo certo, idade própria para ter acesso ao conhecimento.

11 Por uma questão política, só utilizaremos "analfabetos" nas citações, fora isso utilizaremos o termo não alfabetizados ou pessoas não alfabetizadas, por
} 
Numa tessitura mais completa e rica em cores, linhas, fios e possibilidades, a EJA deve ser entendida como um processo de libertação dos sujeitos (FREIRE, 2014). Uma oportunidade de tecer novos caminhos e de fortalecimento, como cidadãos, como jovens e adultos, enquanto homem e mulher. Como afirma Silvana Cortada (2013, p. 7),

Numa visão mais abrangente, a função da Educação de Jovens e Adultos, muito mais do que a recuperação de um tempo de escolaridade perdido, é o de cumprir um papel emancipador e libertar o indivíduo-sujeito das limitações impostas pelo analfabetismo ou pela semialfabetização, facilitando-lhe o processo de escolhas e possibilitando a compreensão e a transformação da realidade. [...].

Trata-se, portanto, de defender a dimensão política da Educação e da alfabetização de jovens, adultos e idosos. É a defesa de uma educação libertadora e emancipadora, possibilitando autonomia para que os sujeitos possam tomar posições e assumir seu espaço de direito na sociedade, participando, com responsabilidade, na tomada de decisões em seus espaços de atuação.

Tramando alguns fios, trazendo algumas cores, possibilidades e fazendo o entrelaçamento da Educação de Jovens e Adultos com a Alfabetização de Adultos, apresentamos, mais uma vez, as ideias inovadoras e inspiradoras de Paulo Freire (2001, p. 25) ao cenário educacional brasileiro, o qual nos elucida que

Além de um ato de conhecimento, a educação é também um ato político. É por isso que não há pedagogia neutra. Não basta dizer que a educação é um ato político assim como não basta dizer que o ato político é também educativo. É preciso assumir realmente a politicidade da educação. Não posso pensar-me progressista se entendo o espaço da

compreendermos que o termo "analfabeto" traz uma carga de preconceito, pois remete à ideia de enfermidade, incapacidade, preguiça. De um sujeito que está perdido e que precisa ser salvo. Como não compactuamos com essa ideia, utilizaremos o termo não alfabetizados ou alfabetizandos. 
escola como algo meio neutro, com pouco ou quase nada a ver com a luta de classes, em que os alunos são vistos apenas como aprendizes de certos objetos de conhecimento aos quais empresto um poder mágico. Não posso reconhecer os limites da prática educativo-política em que me envolvo se não sei, se não estou claro em face de a favor de quem pratico. $\mathrm{O}$ a favor de quem pratico me situa num certo ângulo, que é de classe, em que divisa o contra quem pratico e, necessariamente, o por que pratico, isto é, o próprio sonho, o tipo de sociedade de cuja invenção gostaria de participar.

Com isso, Freire traz ao debate a educação como um ato político, portanto não é neutra. Dessa forma, pensar os processos de alfabetização de adultos é refletir sobre os sujeitos, seus processos, suas subjetividades. Pensar as relações entre educandos, educadores, sociedade, avaliações, currículos, metodologias, formação, conhecimento, saberes.

Dessa forma, revela-se importante destacar que a nossa sociedade está em constante transformação, seja ela de cunho social, cultural, econômico, político, histórico ou tecnológico. E é necessário que os sujeitos que compõem a EJA acompanhem essas mudanças, pois a educação deve oportunizar aos sujeitos participarem plena e conscientemente dessa metamorfose e possibilitar aos jovens, adultos, idosos, aos grupos marginalizados a oportunidade de inclusão, de participação, "um salto a caminho da liberdade". Como Freire (2003, p. 40) nos informa:

A educação como prática de liberdade, ao contrário daquela que é a prática da dominação implica a negação do homem abstrato, isolado, solto, desligado do mundo, assim também a negação do mundo como uma realidade ausente dos homens.

É esta perspectiva da educação como libertação e não como dominação, de uma educação/alfabetização que promova autonomia, politicidade, participação social e envolvimento responsável dos sujeitos nos mais diversos espaços e situações comunicativas de leitura e escrita que, assim como Freire (2003), 
defendemos. E a EJA deve falar deste lugar libertador, de modo que os sujeitos saiam do não lugar de direitos e passem a assumir o seu espaço.

Após termos cortado esses fios da EJA, fios de força, de luta, de equilíbrios, de desequilíbrios, de possibilidades, devemos levá-los para a "urdideira" e devemos urdi-los com a Alfabetização e Práticas pedagógicas.

\section{ALFABETIZAÇÃo E PRÁtICAS PEDAGógICAS: Fios que se entrelaçam}

Para que possamos realmente utilizar os fios na urdidura ${ }^{12}$ é necessário que abordemos as concepções de alfabetização, demonstrando os diversos significados que essa área apresenta no decorrer do tempo e como isso, na maioria das vezes, causa uma problemática no campo e, desse modo, dificulta a qualificação e desenvolvimento das ações.

Para conceituar a alfabetização é necessário explanar que esta, muitas vezes, é confundida pela própria EJA, sendo vista como um sinônimo da mesma. Desse modo, não é possível fazer uma distinção entre essas áreas, com isso ocorre uma ruptura no entendimento desses fios, pois eles são complementares, porém são/têm objetivos distintos. Fernandes (2002, p. 32) nos corrobora afirmando que

[...] Essa indistinção traz ainda em seu bojo outra dificuldade: a própria indefinição conceitual da educação de adultos. O fato é que devido aos altos percentuais de analfabetismo encontrados na população usuária da educação de jovens e adultos no Brasil, América Latina e Caribe, fala-se quase sempre se referindo à alfabetização, provocando certa restrição a esse campo de estudos. [...].

\footnotetext{
12 Trazemos a ideia de fios, urdideira, trama, tessitura, no decorrer do texto, como uma metáfora de que pensar a Educação de Jovens e Adultos é pensar um artesanato de ideias, de pensamentos, de sentidos. Como pensar a criação no tear de diversos tecidos, retalhos. Algo feito individualmente e coletivamente, por diversas mãos, diversos fios, diversas histórias.
} 
A fim de possibilitar uma compreensão mais ampla e buscando fazer uma distinção entre a EJA e a AJA, precisamos entender que discutir a alfabetização significa revelar os desafios, as dificuldades, os anseios, as esperas e os desejos que urdem essa área, e pensando em que direção estamos discorrendo e olhando para alfabetização, de forma mais explícita sobre a sua funcionalidade: como um direito e possibilidades ou como um fim em si mesmo. Lamy (2010, p. 7) corrobora com essas discussões quando assim elucida:

No Brasil, as altas taxas de analfabetismo estão a exigir uma tomada de posição. Como ponto de partida, torna-se prioritário compreender a alfabetização, não como um fim em si mesma (visando apenas o domínio de habilidades técnicas codificação/decodificação dos signos alfabéticos), mas sobretudo, como direito e possibilidade de cidadãos (as) alimentarem suas vivências colhendo frutos que culminarão com a leitura e melhor compreensão do mundo em que vivem.

Para que possamos deixar mais evidente de que lugar estamos falando e pensando, trazemos os conceitos de alfabetização a partir das 05 (cinco) concepções de alfabetização conforme Lamy (2010): representacional, mecânica, funcional, revolucionária e conscientizadora. Nas suas palavras evidencia:

O conceito de alfabetização tem sido objeto de pesquisas e discussões nas últimas décadas. [...] Dada a importância dos múltiplos enfoques no conceito de alfabetização, que discutiam o papel do sujeito-alfabetizador, do mediador-alfabetizador e o objeto a ser construído, vários campos da produção científica foram chamados a colaborar para nortear pesquisas que pudessem elucidar a complexa problemática da construção humana de leitura e escrita. (LAMY, 2010, p. 24).

Quando urdimos o fio da Concepção Representacional, trazemos como fundamento principal os estudos de Emília Ferreiro (1996), que destaca a alfabetização enquanto processo e que esta 
acontece na interação com o meio que cerca o sujeito, construindoo. O professor é um problematizador, a ele cabe criar um ambiente que propicie ao sujeito condições de (re) elaborar suas hipóteses a respeito do mundo. O educando, por sua vez, é sujeito ativo da sua própria aprendizagem. Lamy (2010, p. 30) nos afirma que nessa concepção

Aprende-se a ler no contato com o mundo. O significado das palavras vai-se configurando no decorrer das experiências de vida. [...] A construção da capacidade de produzir e compreender as mais diversas linguagens está diretamente ligada às condições propícias para ler, para dar sentido a expressões formais e simbólicas, representacionais ou não, quer sejam configuradas pela palavra, quer pelo gesto, pelo som e pela imagem.

Com mais fios para urdidura, trazemos à luz a Concepção Mecânica que tem como principal definição o domínio da leitura e escrita do código linguístico. Nessa concepção o aluno é visto como objeto de sua aprendizagem e o professor, por sua vez, segue procedimentos já pré-estabelecidos na construção da aprendizagem. "[...] os conceitos trabalhados nesse estudo são os de sequência cumulativa, cadeias de respostas, ritmo individualizado e avaliação imediata." (LAMY, 2010, p. 32).

A Concepção Funcional, por seu turno, define que alfabetizar é dominar o alfabeto independentemente de sua funcionalidade de ser alfabetizado. Nesse fio da urdidura, o que importa é que os sujeitos tenham conhecimento total do código linguístico. "Fica implícito, pois o aspecto funcional da alfabetização - que, dessa forma, serve à sociedade, tal como está constituída em classes". (LAMY, 2010, p. 33).

Para termos uma boa tessitura, é importante que continuemos urdindo esses fios e, com isso, chega o momento de entrelaçar os fios das Concepções Revolucionárias; esses fios, por si, já trazem novas ideias, novos pensamentos muitas vezes contrários aos que já foram apresentados até aqui, pois são antagônicas as ideias de que a leitura e a escrita devem atender à valorização do mercado de trabalho, ao aprisionamento da classe trabalhadora e a 
uma forma de adquirir mais lucro para as classes dominantes. Lamy (2010, p. 35) elucida sobre essa temática ao destacar que:

[...] essas experiências tiveram início na Revolução russa de 1917, onde a luta contra o analfabetismo fez parte integrante. Em 1923, a organização voluntária chamada "abaixo o analfabetismo" mobilizou pessoas para a campanha de alfabetização nacional. O país tornou-se uma grande escola. Os índices de analfabetismo foram, em 1917 = 75\%; em 1923 = 43\%; e em $1939=11 \%$.

Agora serão urdidos os fios da Concepção que alicerça nossa pesquisa e nos embasa: a Conscientizadora. Falar de uma perspectiva conscientizadora significa trazer os ensinamentos, as palavras, os versos, as obras, a boniteza de Paulo Freire, mais uma vez, ao nosso texto. Quando falamos em alfabetizar nessa perspectiva, a primeira coisa que devemos esclarecer é que o homem é sujeito da sua aprendizagem e não objeto, como defendido em outras concepções. Ele é autônomo, tem papel ativo e dialógico com o mundo que o cerca. É nessa tessitura que Freire (2011, p. 11-12) nos abrilhanta com sua afirmação de que

[...] A leitura do mundo precede a leitura da palavra, daí que a posterior leitura desta não pode prescindir da continuidade da leitura daquele (A palavra que eu digo sai do mundo que estou lendo, mas a palavra que sai do mundo que eu estou lendo vai além dele). [...] Se for capaz de escrever minha palavra estarei, de certa forma transformando o mundo. $\mathrm{O}$ ato de ler o mundo implica uma leitura dentro e fora de mim. Implica na relação que eu tenho com esse mundo.

Entrelaçamos os fios com as ideias de Paulo Freire e destacamos que quando falamos de alfabetização estamos trazendo elementos e ideias que vão além de ideias dicotômicas, ou pensamentos que reduzem $\circ$ processo alfabetizador à codificação/decodificação dos códigos linguísticos, ou meramente ensinar/aprender; educando/educador. Estamos, no entanto, dialogando com homens, mulheres, jovens, adultos que têm suas 
histórias, suas identidades, seus saberes, uma vez que alfabetizar, segundo Freire e Macedo (2013, p. 70), é

[...] inerentemente, um projeto político no qual homens e mulheres, afirmam seu direito e responsabilidade não apenas de ler, compreender e transformar suas experiências pessoais, mas também de reconstruir sua relação com sociedade mais ampla. Promovendo a conscientização acerca dos problemas cotidianos, a compreensão do mundo e o conhecimento da realidade social.

Com isso, Ann E. Berthoff, no segundo prefácio do livro Alfabetização: leitura de mundo, leitura da palavra (FREIRE; MACEDO, 2013), respaldada nos estudos de Paulo Freire, fornece-nos uma grande lição: quando falamos de Alfabetização devemos estar sempre atentos, vigilantes, ativos, mas o mais importante é que devemos saber olhar, pois

[...] No campo da teoria da alfabetização, nada é mais importante do que olhar e olhar novamente para o papel de uma percepção do perceber, de pensar sobre o pensamento, de interpretar nossas interpretações. (p. 11-12).

Precisamos compreender quem somos, quais nossos papéis e como podemos modificar a realidade que nos cerca e, dessa forma, como atrelá-la às práticas pedagógicas. É nesta perspectiva que "urdiremos" em seguida.

\section{Práticas Pedagógicas}

Para pensarmos as Práticas Pedagógicas, primeiro necessitamos compreender de que lugar estamos partindo, desse modo precisamos entender que nosso país, Brasil, é considerado de acordo com a Organização das Nações Unidas (ONU) um país emergente, ou seja, o panorama brasileiro apresentou, de fato, evoluções econômicas e sociais em relação a algumas décadas, mas não se livrou de várias condições sociais, econômicas e historicamente constituídas que o levaram ao subdesenvolvimento, 
tais como: a concentração de renda elevada, o limitado desenvolvimento humano, a baixa qualidade em termos de educação e saúde, as limitações de infraestrutura, entre muitas outras (PENA, 2012).

É nesse cenário que a educação precisa de investimentos públicos e os educadores de práticas pedagógicas que levem em consideração esses fatos. Nessa conjectura, Paulo Freire recorda-nos na Pedagogia do Oprimido que uma educação libertadora possibilita ao sujeito o reconhecimento da sua situação de oprimido e a luta pela sua liberdade. Nas suas palavras, evidencia:

[...] Quem, melhor que os oprimidos, se encontrará preparado para entender o significado terrível de uma sociedade opressora? Quem sentirá, melhor que eles, os efeitos da opressão? Quem, mais que eles, para ir compreendendo a necessidade da libertação? Libertação que não chegaram por acaso, mas pela práxis de sua busca; pelo conhecimento e reconhecimento da necessidade de lutar por ela (FREIRE, 2014, p. 31-32).

É partindo destas problematizações de Freire que urdimos os fios das Práticas Pedagógicas. Para tanto, faz-se necessário, primeiro, refletir sobre o ato de ensinar, o qual, de acordo com Paulo Freire (2015, p. 25), "[...] do ponto de vista gramatical, o verbo ensinar é um verbo transitivo relativo. Verbo que pede um objeto direto - alguma coisa - e um objeto indireto - a alguém". Todavia, para Freire, ensinar não se abrevia somente a um verbo transitivo relativo,

[...] ensinar inexiste sem aprender e vice-versa, e foi aprendendo socialmente que, historicamente, mulheres e homens descobriram que era possível ensinar. [...] Não temo dizer que inexiste validade no ensino de que não resulta de um aprendizado em que o aprendiz não se tornou capaz de recriar ou de refazer o ensinado, em que o ensinado que não foi apreendido não pode ser realmente aprendido pelo aprendiz (FREIRE, 2015, p. 26).

Nesse cenário, as práticas pedagógicas trazem no seu bojo a necessidade de entendermos os saberes, as concepções e o lugar de 
onde estamos partindo e como estes aspectos alicerçam nosso fazer docente e nossas ações educativas. Desse modo, pensar a educação, o processo de ensino/aprendizagem está diretamente vinculado a perspectivas políticas e sociais, compreendendo, assim, a educação como um "fenômeno social" (LIBÂNEO, 2013).

Mergulhados neste cenário da alfabetização e das práticas pedagógicas, o educador, como um dos sujeitos envolvidos no processo de alfabetização, precisa de uma preparação adequada, tanto na sua base teórica, pedagógica, curricular, didática e metodológica, quanto na questão da adequação à realidade vivida pelos educandos.

Dessa forma, é preciso que se discutam elementos básicos da educação todos alicerçados no planejamento, no estudo, no diálogo, pois, para que haja uma prática pedagógica que leve em consideração a realidade dos sujeitos, faz-se necessária reavaliação das práticas, além de acompanhamento rigoroso das atividades desenvolvidas, luta por uma educação de qualidade (para que se valorizem os profissionais da educação).

Ressaltamos o entendimento/reconhecimento de que a educação libertadora é hoje, mais do que nunca, uma tarefa a ser preservada, pois diariamente deparamo-nos com discursos governamentais que prometem grandes reformas e investimentos na educação e, infelizmente, o que vemos são apenas palavras que não se tornam concretas. Diante disso, vivenciamos recorrentemente no cenário educacional evasões, reprovações, desvalorização dos profissionais da educação.

No entanto, é na sala de aula que esse problema pode ser trabalhado. Na parceria entre educador e educando, num ambiente de acolhimento, de inovação, de criatividade, de amizade, de respeito, de amor, de libertação. Aqui cabe ao educador o dever de conhecer, orientar, dialogar, mediar o educando e com ele criar práticas que permitam vivenciar o ambiente de ensino/aprendizagem. Assumir práticas pedagógicas na EJA significa compreender que fios não são apenas reprodução de trabalho, ou trabalhar de forma infantilizada, mas, sim, compreender que esses sujeitos são protagonistas das suas histórias, das suas cores, dos seus fios, das suas tramas. 


\section{DISCUSSÕES E RESULTADOS: "A trama”}

Os fios que fomos tecendo até aqui convidam-nos a pensar a problemática da Alfabetização e das Práticas Pedagógicas na EJA, linhas que são alicerçadas numa discussão desafiadora, atual e necessária. Freire, em suas escritas, convida-nos a ampliar nossos conhecimentos, compreendendo que somos seres inconclusos e que estamos em estado de constante aprendizado. Nessa perspectiva, precisamos entender que quando falamos de não alfabetização ela vem carregada de incertezas, de inconstâncias, de reticências, de desvios, de esperas.

Nessa conjuntura, as situações do INAF trazem-nos indicativos de que os educandos encontram-se em níveis de proficiência ${ }^{13}$, isto é, não alfabetizado, rudimentar e elementar, na escala do Alfabetismo Funcional, conforme pode ser visualizado no Gráfico 1, a seguir:

Gráfico 01: Indicador de Analfabetismo Funcional

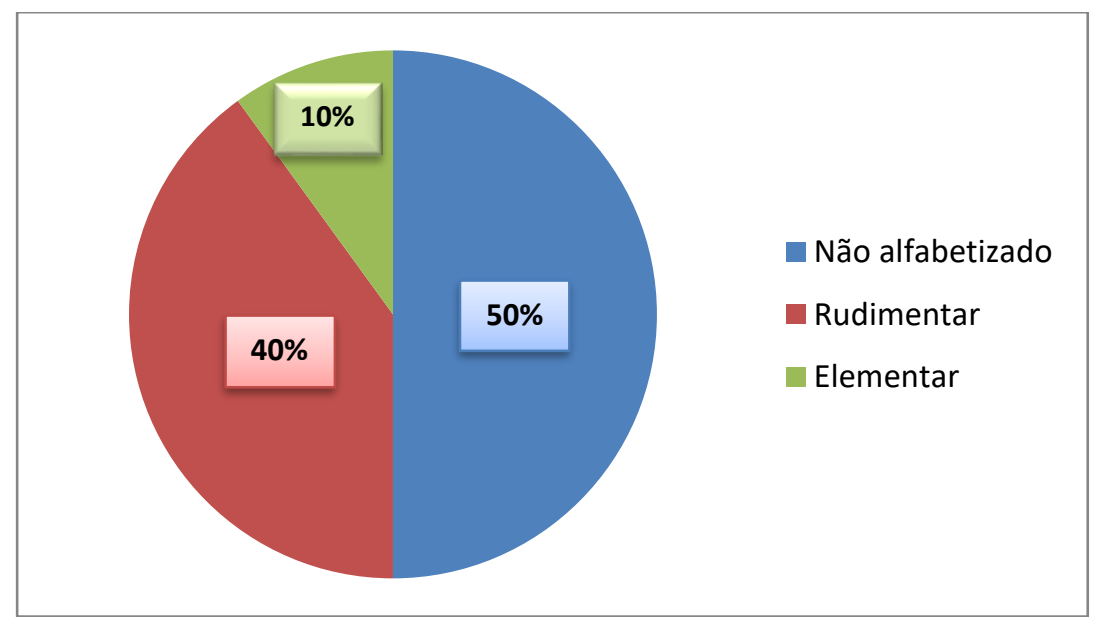

Fonte: Dados produzidos pelas pesquisadoras com os educandos do Colégio Entre Fios.

Ao tramar as falas das educadoras com os dados do gráfico 1 , percebemos que os educandos encontram-se nos níveis Não

\footnotetext{
${ }^{13}$ Estes níveis de proficiência serão explicados após apresentação do gráfico.
} 
alfabetizado, Rudimentar e Elementar da escala de Proficiência do Alfabetismo Funcional. Com isso, observamos que, apesar de já estarem no Ensino Médio na modalidade da EJA, estes não alcançaram os níveis mais altos da escala do Alfabetismo, ou seja, o Intermediário e o Proficiente, como seria esperado para este grau de escolaridade.

Os números apontam que $50 \%$ dos educandos são considerados não alfabetizados, ou seja, "corresponde à condição dos que não conseguem realizar tarefas simples que envolvem a leitura de palavras e frases ainda que uma parcela consiga ler números familiares (de telefone, preços etc.)." (INAF, 2018, p. 22).

Esses dados são gritantes e apontam uma realidade contraditória com os objetivos da modalidade da EJA e com as políticas públicas direcionadas à educação, pois estamos falando de uma parcela da população que está finalizando os estudos da educação básica. Homens e mulheres cheios de sonhos, expectativas, desejos, anseios por conseguir o primeiro emprego, se qualificarem para a busca de melhores oportunidades de emprego e salários, o ingresso em cursos técnicos e universidades, mas que estão privadas de uma alfabetização funcional.

Continuando a tramar esses dados, percebemos que $40 \%$ desses sujeitos encontram-se no nível rudimentar que é caracterizado por

[...] Localizar uma ou mais informações explícitas, expressas de forma literal, em textos muito simples (calendários, tabelas simples, cartazes informativos) compostos de sentenças ou palavras que exploram situações familiares do cotidiano doméstico.

Compara, lê e escreve números familiares (horários, preços, cédulas/moedas, telefone) identificando o maior/menor valor.

Resolve problemas simples do cotidiano envolvendo operações matemáticas elementares (com ou sem uso da calculadora) ou estabelecendo relações entre grandezas e unidades de medida.

Reconhece sinais de pontuação (vírgula, exclamação, interrogação etc.) pelo nome ou função. (INAF, 2018, p. 21). 
Ademais, $10 \%$ desses educandos encontram-se no nível elementar, que tem por características

[...] Selecionar uma ou mais unidades de informação, observando certas condições, em textos diversos de extensão média realizando pequenas inferências.

Resolve problemas envolvendo operações básicas com números da ordem do milhar, que exigem certo grau de planejamento e controle (total de uma compra, troco, valor de prestações sem juros).

Compara ou relaciona informações numéricas ou textuais expressas em gráficos ou tabelas simples, envolvendo situações de contexto cotidiano doméstico ou social.

Reconhece significado de representação gráfica de direção e/ou sentido de uma grandeza (valores negativos, valores anteriores ou abaixo daquele tomado como referência). (INAF, 2018. p. 21).

Centrados e mergulhados nessa tessitura, dialogamos com Arroyo (2005), ao elucidar que vivenciamos uma "cultura de exclusão" social, que favorece através do campo educacional um meio para manutenção e controle da sociedade. Com esses "fracassos", os sujeitos não compreendem e não lutam por condições melhores de vida, centradas em aspectos políticos, sociais, econômicos e históricos.

Corroboramos com Arroyo (2015) quando nos convida a pensar a própria função da educação, da pedagogia, ao problematizar: no que está centrada a função do educador, do ensinar? Por que, muitas vezes, estamos tão vinculados ao que está sendo trabalhado, às nossas funções e aos papéis que assumimos que deixamos de aguçar nossa visão, esquecemos de ressignificar nossos olhares, de buscarmos compreender quem são os sujeitos da EJA? Qual o sentido da EJA? Qual o sentido do educar? Qual o sentido do aprender?

Nessa tessitura, é de fundamental importância que o educador, nesse caso da EJA, tenha clareza de que seus educandos são seres históricos e que, por isso, trazem consigo "mochilas" cheias de saberes, as quais foram adquiridas através de experiências pessoais e/ou por passagens por outros processos escolares, que 
devem ser valorizados e aproximados dos científicos. Dessa forma, pensar as práticas pedagógicas como uma ação em movimento, que vai e volta, que se desvia, que surge, que se completa, que se estende, é perceber que essas características podem ser

[...] uma riqueza para o fazer educativo. Quando os interlocutores falam de coisas diferentes, o diálogo possível. Quando só os mestres têm o que falar não passa de um monólogo. Os jovens e adultos carregam as condições de pensar sua educação como diálogo. Se toda educação exige uma deferência pelos interlocutores, mestres e alunos (as), quando esses interlocutores são jovens e adultos carregados de tensas vivências, essa deferência deverá ter um significado educativo especial. (ARROYO, 2005, p. 35).

Nesse ínterim, precisamos dialogar com as questões que são cruciais para pensarmos uma educação de qualidade, centrada na valorização do sujeito, que compreenda os contextos, as realidades e as questões que atravessam a EJA e suas especificidades.

\section{(IN) CONCLUSÕES: “O amarrar dos fios"}

Chegamos ao momento de "amarrar os fios", os quais foram urdidos, para, em seguida, serem trançados juntamente com as linhas, com muita humildade, respeito, paciência e delicadeza, para a construção desta trama que foi atravessada por diversos fatores e sentimentos. Por isso, estamos trazendo apontamentos, considerações, caminhos que foram sendo desenhados, apontados no desdobramento da investigação.

Destacamos que esses fios são forjados em lutas, resistências, são moldados entre avanços e retrocessos, entre equilíbrios e desequilíbrios. Esta investigação convidou-nos e convida-nos a pensarmos quem são os sujeitos da EJA ou, como informa Arroyo (2017), quem são os "passageiros da noite" que formam e são formados na modalidade.

Destacamos, mais uma vez, que alfabetizar vai além da codificação/decodificação dos códigos linguísticos, ela é mais do que 
simplesmente uma função, um meio de que o mundo, a sociedade continue do jeito que está. Além de ler e escrever, ela significa compreender nosso lugar, quem somos, as influências que sofremos, é uma forma de transformação.

A problemática aqui apresentada foi tecida para além de anseios, desejos pessoais já apresentados durante a construção deste texto, mas também da necessidade apresentada pelo campo por pesquisas que realmente mergulhem no universo da alfabetização e das práticas pedagógicas e isso foi evidenciado nos dados da pesquisa, ao revelarem que os indicadores de alfabetismo no Ensino Médio são assustadores e estão aquém do que é esperado para estudantes da última etapa da Educação Básica.

Dessa forma, como estamos tratando de (in) conclusões, deixaremos algumas questões que acreditamos serem importantes ao pensar a EJA: qual o sentido da EJA? O processo formativo é pensado para uma dimensão humana? Ou simplesmente para uma aquisição dos códigos linguísticos? Quais dimensões atravessam os sujeitos que formam a modalidade? Como pensar uma educação que valorize o sujeito em suas diversas multidimensionalidades?

Esses questionamentos são pensados em uma tessitura que busca produzir uma reflexão do sentido da AJA e das práticas pedagógicas na EJA e o sentido da própria modalidade. Essas fagulhas que foram acesas convidam-nos a ter um olhar mais humilde, mais atento e a tencionar políticas públicas voltadas ao investimento e valorização da EJA.

\section{REFERÊNCIAS}

ARROYO, Miguel G. Educação de Jovens e Adultos: um campo de direitos e de responsabilidade pública. In: SOARES, Leôncio; GIOVANETTI, Maria Amélia Gomes de Castro; GOMES, Nilma Lino (Org.). Diálogos na Educação de Jovens e Adultos. 2 ed. Belo Horizonte: Autentica, 2005.

ARROYO, Miguel G. Passageiros da noite: do trabalho para a EJA: itinerários pelo direito a uma vida justa. Petrópolis. RJ: Vozes, 2017. 
ARROYO, Miguel G. O humano é viável? É educável?. Revista Pedagógica, Chapecó, v. 17, n. 35, p. 21-40, maio/ago. 2015. Disponível em< https://bell.unochapeco.edu.br/revistas/index.php/pedagogica/articl e/view/3052 >. Acesso em: 13. mar. 2021.

BRASIL. Instituto Brasileiro de Geografia e Estatística (IBGE). Pesquisa Nacional por Amostra de Domicílios Contínua. Educação 2019. 2020 Disponível em: https://biblioteca.ibge.gov.br/visualizacao/livros/liv101736_informati vo.pdf. Acesso em: 15. mar. 2021

CORTADA, Silvana. EJA - Educação de Jovens e Adultos e seus diferentes contextos. Jundiaí, Paco Editorial: 2013.

FERNANDES, Dorgival Gonçalves. Alfabetização de jovens e adultos: pontos críticos e desafios. Porto Alegre: Mediação, 2002.

FERREIRO, Emília. Alfabetização em Processo. São Paulo: Cortez, 1996. 144p.

FREIRE, Paulo. Política e Educação. 5 ed. Editora Cortez, São Paulo, 2001.

FREIRE, Paulo. A importância do ato de ler. Editora Cortez, São Paulo, 2003.

FREIRE, Paulo. Pedagogia do oprimido. 57. ed. Rio de Janeiro: Paz e Terra, 2014.

FREIRE, Paulo. Pedagogia da Autonomia: saberes necessários à prática educativa. 52. ed. Rio de Janeiro: Paz e Terra, 2015.

FREIRE, Paulo. Pedagogia da Esperança: um reencontro com a pedagogia do oprimido. 22. ed. São Paulo: Paz e Terra, 2018.

FREIRE, Paulo; MACEDO, Donaldo. Alfabetização: Leitura do mundo, leitura da palavra. Tradução de: OLIVEIRA, Lólio Lourenço de. 6. ed. Rio de Janeiro: Paz e Terra, 2013.

INAF. Indicador de Alfabetismo Funcional. Inaf Brasil 2018: resultados preliminares. Ação educativa, Instituto Paulo Montenegro, Ação Social do IBOPE. 2018. Disponível em: 
https://acaoeducativa.org.br/wp-

content/uploads/2018/08/Inaf2018_Relat\%C3\%B3rio-ResultadosPreliminares_v08Ago2018.pdf. Acesso em: 01 mar. 2021.

LAMY, Gersolina Antônia de Avelar. Panorama da alfabetização no Brasil. In: LAMY, Gersolina Antônia de Avelar; HOELLER, Solange Aparecida de Oliveira (org.) Alfabetização em destaque. Campinas, Mercado de Letras, 2010.

LAKATOS, Eva Maria; MARCONI, Marina A. Metodologia Científica. 5. ed. São Paulo: Atlas, 2005.

LIBÂNEO, José Carlos. Didática. 2. ed. São Paulo: Cortez, 2013.

LÜDKE, Menga; ANDRÉ, Marli E. D. A. Pesquisa em educação: abordagens qualitativas. São Paulo: EPU, 1986.

PENA, Rodolfo F. Alves.

"Brasil: subdesenvolvido ou

emergente?"; Brasil Escola, 2012. Disponível em: https://brasilescola.uol.com.br/brasil/brasil-subdesenvolvido-ouemergente.htm. Acesso em: 16 maio 2019.

RIBEIRO, Vera Masagão. Por mais e melhores leitores: uma introdução. In: RIBEIRO, Vera Masagão. (Org.) Letramento no Brasil: reflexões a partir do INAF 2001. São Paulo: global, 2003. p. 929.

SÁ, Maria Reneude de. Analfabetismo e alfabetização: representações de professores alfabetizadores. Curitiba: Appris, 2016.

TORRES, Rosa Maria. Cinco Reflexões sobre Educação. Revista Alfabetização e Cidadania. v. 2, n. 1. São Paulo: RAAB - Rede de Apoio à Ação Alfabetizadora do Brasil, 1995.

Submetido em: Junho/ 2021.

Aceito em: Agosto/ 2021. 